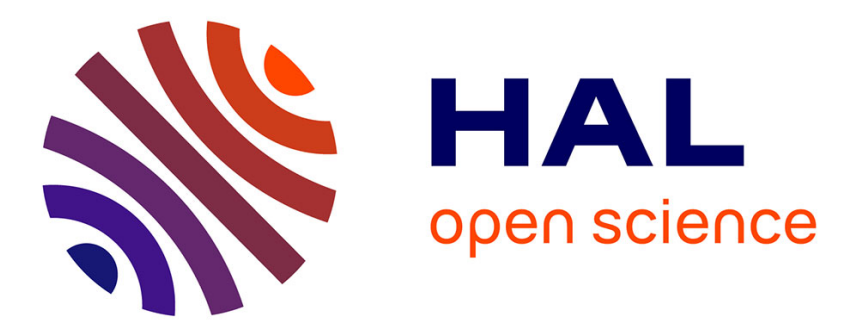

\title{
The symbiosis between Philidris ants and the ant-plant Dischidia major includes fungal and algal associates
}

\author{
Rumsais Blatrix, Aroonrat Kidyoo, Manit Kidyoo, Jittra Piapukiew,
} Anchittha Satjarak, Chanita Paliyavuth, Wachana Boonchai, Doyle Mckey

\section{- To cite this version:}

Rumsais Blatrix, Aroonrat Kidyoo, Manit Kidyoo, Jittra Piapukiew, Anchittha Satjarak, et al.. The symbiosis between Philidris ants and the ant-plant Dischidia major includes fungal and algal associates. Symbiosis, 2021, 83 (3), pp.305-315. 10.1007/s13199-021-00751-x . hal-03358013

\section{HAL Id: hal-03358013 \\ https://hal.science/hal-03358013}

Submitted on 29 Sep 2021

HAL is a multi-disciplinary open access archive for the deposit and dissemination of scientific research documents, whether they are published or not. The documents may come from teaching and research institutions in France or abroad, or from public or private research centers.
L'archive ouverte pluridisciplinaire HAL, est destinée au dépôt et à la diffusion de documents scientifiques de niveau recherche, publiés ou non, émanant des établissements d'enseignement et de recherche français ou étrangers, des laboratoires publics ou privés. 
The symbiosis between Philidris ants and the ant-plant Dischidia major includes fungal and algal associates

Rumsaïs Blatrix ${ }^{1}$, Aroonrat Kidyoo²*, Manit Kidyoo², Jittra Piapukiew ${ }^{3}$, Anchittha Satjarak $^{2}$, Chanita Paliyavuth ${ }^{3}$, Wachana Boonchai ${ }^{4}$, Doyle McKey ${ }^{1}$

${ }^{1}$ CEFE, University of Montpellier, CNRS, EPHE, IRD, University Paul Valéry Montpellier 3, Montpellier, France

${ }^{2}$ Plants of Thailand Research Unit, Department of Botany, Faculty of Science, Chulalongkorn University, Pathumwan, Bangkok 10330, Thailand

${ }^{3}$ Department of Botany, Faculty of Science, Chulalongkorn University, Pathumwan, Bangkok 10330, Thailand

${ }^{4}$ Rayong Botanical Garden, Rayong, Thailand

\section{* Corresponding author:}

Aroonrat Kidyoo

E-mail: aroonratm@hotmail.com

Plants of Thailand Research Unit, Department of Botany, Faculty of Science, Chulalongkorn University, Pathumwan, Bangkok 10330, Thailand

ORCID of the authors:

Rumsais Blatrix 0000-0003-1662-7791

Aroonrat Kidyoo 0000-0003-2590-2441 
Manit Kidyoo 0000-0003-1740-9999

Anchittha Satjarak 0000-0003-3844-6924

Doyle McKey 0000-0002-7271-901X 


\begin{abstract}
Dischidia major is an epiphyte with pitcher leaves that serve as nests for ants. We investigated this ant-plant symbiosis in two sites in southeastern Thailand, Rayong and Trat, using a morphological and molecular approach. In our study sites, D. major was colonized by one monomorphic ant species of genus Philidris. The inner surface of the pitcher leaves had a black and green lining composed of intermingled coccoid cells and filaments of algae and fungi, reminiscent of a biofilm structure. Microscopic investigation of the algae suggested they belonged to Trebouxia (coccoid cells) and Trentepohliaceae (filaments). Molecular investigation of environmental samples and pure cultures of the fungi revealed five species of Chaetothyriales and four species of Capnodiales, among which two have already been isolated from ant-plant symbioses in Africa and South America and five were described species known from various environments around world. One appears to be an undescribed species. Thus, most fungal associates were likely ubiquitous species. Our study highlights the need to include the identity and functional ecology of microbes in studies of the evolutionary and functional ecology of ant-plant symbioses.
\end{abstract}

Keywords Apocynaceae-Asclepiadoideae · black fungi · Dolichoderinae · myrmecophyte $\cdot$ Trebouxia $\cdot$ Trentepohliaceae 


\section{Declarations}

\section{Funding}

This research was supported by 'Franco-Thai Mobility Programme (PHC SIAM, France) 2018-2019' (project number 40533RA), by the programme 'International Emerging Actions' of the CNRS, France (project FOOLFLY 2020-2021), and by Chulalongkorn University: CU-GR_61_020_23_007.

\section{Conflicts of interest/Competing interests}

The authors declare that there is no conflict of interest.

\section{Ethics approval}

Not applicable.

\section{Consent to participate}

Not applicable.

\section{Consent for publication}

Not applicable.

\section{Availability of data and material}

All DNA sequences that support the findings of this study are publicly available in GenBank at http://www.ncbi.nlm.nih.gov/genbank/.

\section{Code availability}

Not applicable.

\section{Running title}

Fungi and algae in an ant-plant symbiosis 


\section{Introduction}

Ants are involved in symbiotic interactions with an incredible diversity of organisms. Among these, plants are among the most conspicuous, and have drawn the attention of biologists since the middle of the 19th century at least. There are about 700 known species of myrmecophytes (or ant-plants), i.e. plants that are involved in symbiotic interactions with ants through the production of hollow structures in which an ant colony can dwell. Ants that live only in such plants are termed 'plant-ants' (see Webber et al. [2007] for discussion of terminology). Myrmecophytes are scattered across 50 plant families, involving at least 158 independent evolutionary origins, and are most commonly encountered in the inter-tropical belt (Davidson and McKey 1993; Chomicki and Renner 2015). Ant-housing hollow structures, called domatia, have various anatomical origins, and can be derived from stems, stipules, petioles, leaves, tubers, and rhizomes. They are usually conspicuously swollen. Many myrmecophytes provide food directly to the ant colony, in the form of extra-floral nectar or through the production of food bodies, structures that are particularly rich in proteins, lipids and/or carbohydrates, and sometimes contain glycogen, a complex sugar used for energy storage in animals and fungi but extremely rare in plants (Heil and McKey 2003). Resident ants also often get food from the plant indirectly through the rearing of sapsucking hemipterans within the domatia (Heil and McKey 2003). Thus, the ant colony obtains benefits of food and lodging from the symbiosis. In return, the plant benefits from protection by the ants against herbivores (invertebrates as well as vertebrates), pathogens and encroaching vegetation (Heil and McKey 2003). Protection has long 
been considered the main benefit that myrmecophytes get from ants, but recent views consider that nutrient access might be of comparable importance in the evolution of the myrmecophyte strategy (Mayer et al. 2014). Indeed, out of 19 plant species tested, 14 were shown to acquire $\mathrm{N}$ and/or $\mathrm{C}$ (but also $\mathrm{P}$ and $\mathrm{S}$ ) from the activity of symbiotic ants (Mayer et al. 2014). How these nutrients are acquired by the plant remains unknown. Two myrmecophytes were shown to acquire $\mathrm{N}$ and/or $\mathrm{C}$ from small molecules such as simple sugars and amino acids directly through the inner wall of domatia (Defossez et al. 2011; Gegenbauer et al. 2012). However, complex molecules such as those constituting a large part of the waste of an ant colony may not be readily accessible to the plant. Nutrient transfer from ants to plants may rely on the breaking down of complex compounds by microorganisms (Huxley 1978), a reasonable assumption given the recent finding of fungus-mediated transfer of nitrogen from plant-ants to an antplant (Leroy et al. 2011, 2017) and the repeated occurrence of fungi (Mayer et al. 2014) and bacteria (Hanshew et al. 2015; Maschwitz et al. 2016) within ant-occupied domatia.

Ant-plant symbioses have been mostly studied as bipartite interactions, but recent work exploring the identity and the functional role of fungi (and bacteria) has shown them to be fully integrated partners in these systems (Mayer et al. 2014) and ant-plantsymbioses may better be viewed as symbiotic communities (Huxley 1978; Blatrix et al. 2009).

The description of dark patches of filamentous fungi in ant-occupied domatia dates back to the beginning of the 20th century (Miehe 1911). The beneficial nature of these fungi for the ants was recurrently hypothesized (Bailey 1922; Janzen 1972; Huxley 1978; Schremmer 1984), but their taxonomic identity remained unclear because 
of the lack of diagnostic morphological features. It is only during the past decade that the understanding of interactions between plant-ants and fungi made a significant step forward with the re-discovery of dark filamentous fungi within domatia and in cartons made by plant-ants (Defossez et al. 2009; Mayer and Voglmayr 2009). Cartons are materials made by ants from soil particles, wood particles or plant trichomes glued together to build entire nests (either arboreal or in the ground), nesting platforms within cavities (e.g., within domatia) and runway galleries (i.e. tunnels built on plant stems, covering ant trails). Furthermore, culturing and the application of molecular taxonomy in fungi have aided the description of fungi that occur in patches on the inner wall of domatia and in carton structures built by plant-ants. This work has revealed that these fungi belong to the order Chaetothyriales and, to a lesser extent, to the Capnodiales (Mayer et al. 2014). Chaetothyriales and Capnodiales are commonly called 'black fungi' along with other groups in the ascomycete classes Dothideomycetes and Eurotiomycetes. This grouping has no taxonomic or phylogenetic value, but is convenient to designate microcolonial fungi characterized by slow growth, melanized cell walls and high tolerance to extreme environments (Gostinčar et al. 2012). The general view has been that ant-built carton structures harbour a diversity of black fungi and that these fungi are not specific to the ant-plant system (Mayer and Voglmayr 2009; Voglmayr et al. 2011; Nepel et al. 2014, but see Ruiz-González et al. 2011). In contrast, population-level studies showed that composition of fungal patches occurring within domatia varied little within a single ant species and was dominated by a few fungal species (typically one to three) (Blatrix et al. 2013; Kokolo et al. 2016; Nepel et al. 2016). Many chaetothyrialean and capnodialean taxa characterized in ant-plant 
symbioses are undescribed species, but within-domatium fungal patches can also include ubiquitous chaetothyrialean species (Voglmayr et al. 2011; Vasse et al. 2017), highlighting the point that these fungi are understudied and that patterns of specificity are far from being understood.

Although molecular identification of ant-plant associated fungi at the population level has made an important contribution to the understanding of the symbiotic nature of these fungi, the most important step has been the investigation of their functional roles. Fungal hyphae work as reinforcing rods in ant-made carton structures (Dejean et al. 2005; Mayer and Voglmayr 2009), but have also been shown to contribute to the transfer of nutrients from ant activity to the host plant (Leroy et al. 2011, 2017). Chaetothyrialean fungi in dark patches within domatia are propagated by ants across domatia (Huxley 1978; Defossez et al. 2009), transmitted to daughter colonies by founding queens (Mayer et al. 2018), manured by ants (Defossez et al. 2011) and used as food for ant larvae (Blatrix et al. 2012; Mayer et al. 2018). Thus, these fungi are fully integrated in the trophic strategy of plant-ants, but their role in the ant-to-plant trophic flux still remains to be demonstrated.

Dischidia (Apocynaceae, Asclepiadoideae) is a genus of more than 100 species of epiphytic and, less commonly, lithophytic herbs, often climbers, endemic to Asia and Oceania. The genus shows great variation in leaf texture and shape, ranging from coriaceous lanceolate to succulent orbiculate. Leaf shape drives the level of intimacy between the plant and the ants. Most species have leaves lacking any traits that favour association with ants. Several other species have half-dome-shaped leaves appressed against the branch or trunk that serves as support (Livshultz et al. 2005; Rintz 1980; 
Thaithong et al. 2018). In these species, ants colonize and nest in the space between the tree and the epiphyte's leaves. Such an association can be considered symbiotic, but corresponds to an incomplete integration of the ant colony into plant morphology. In a few species, leaf blades are fully rolled and margins fuse so that leaves are pitchershaped. These pitcher leaves can unambiguously be called domatia, and are, in fact, used as nesting sites by ants. Another peculiarity of Dischidia plants is the growth of adventitious roots at nodes (and thus near leaf axils), allowing the plant to climb. This characteristic - which occurs in both species with and without domatia or half-dome structures — can be viewed as a preadaptation that facilitated the exploitation of benefits associated with the presence of ants. In species with half-dome-shaped leaves, adventitious roots grow into the space between the abaxial side of the leaf and the bark of the support tree, a space colonized by ants. Thus, each adventitious root can both secure the attachment of the plant to the support tree and take up nutrients from ant activity. In species with pitcher leaves, adventitious roots grow outside the pitcher but also within the pitcher, where the ants nest. The occurrence of adventitious roots within the pitchers may be an adaptation to taking up nutrients from ant activity, as these roots have lost their primary function (attachment to the support tree).

Myrmecophytic Dischidia are most commonly colonized by Philidris ants. Philidris is a genus of arboreal ants that build carton nests and runway galleries (Kaufmann 2002). When colonizing Dischidia pitcher leaves, they optimize space use by building carton platforms, using adventitious roots as a frame (Kerr 1912; Peeters and Wiwatwitaya 2014). They also accumulate debris within the leaf, eventually filling the domatium (Janzen 1974). Contact with carton or debris induces adventitious roots to 
produce fine root hairs, suggesting that the ants give their host plant access to nutrients in ant-generated materials (Janzen 1974; Peeters and Wiwatwitaya 2014). Nitrogendeprived plants such as epiphytes would greatly benefit from such a strategy (Janzen 1974, Thompson 1981). Indeed, it was reported that Dischidia major (Vahl) Merr. derives $29 \%$ of its nitrogen from symbiotic ants (Treseder et al. 1995). Interestingly, the plant also obtains carbon from the ant colony, probably because ant respiration increases $\mathrm{CO}_{2}$ concentration in pitcher leaves (Treseder et al. 1995). In Dischidia major, the inner surface of the pitcher leaves (i.e. the abaxial surface) has greater stomatal density than the outer surface (i.e. the adaxial surface) (Griffith and Solly 1851). Stomata are thus surrounded by air that is rich in both $\mathrm{CO}_{2}$ and water vapour (ant nests have high humidity), enabling uptake of carbon with little loss of water. Half-domeshaped leaves may be similar in this regard.

Although Pearson (1902) long ago reported fungi from the inner side of pitcher leaves of myrmecophytic Dischidia, the vague description of these fungi and the fact that the study was based on dried herbarium specimens make it uncertain whether these fungi could represent another case of symbiosis between ants, plants and black fungi. In addition, although there have been subsequent studies of myrmecophytism in Dischidia plants, we are not aware of any other mention of fungi within domatia. Preliminary observation of samples of $D$. major from Thailand revealed a black lining reminiscent of the black fungal patches on the inner side of pitcher leaves similar to those we have seen in other myrmecophytes. The black lining had a green tinge in some places, suggesting the presence of algae. These observations prompted us to undertake a deeper investigation of fungi and other symbiotic partners in the ant-plant $D$. major in 
Thailand. Here, we characterised the fungal and algal associates using morphology and sequencing of several DNA regions.

\section{Materials and methods}

The Rayong Botanical Garden (Rayong Province, Thailand, N12.65 E101.55) contains a large swamp where $D$. major is abundant, in particular on Melaleuca quinquenervia (Cav.) S.T. Blake trees (Fig. 1A). We collected 23 samples of D. major occupied by ants, each from a different tree, in July 2018. Each sample consisted of several pitcher leaves collected on the same stem. Pitcher leaves were opened and checked for fungi and algae. Ant specimens were stored in ethanol and deposited in the collections of Salinee Khachonpisitsak (Burapha University, Chon Buri, Thailand), Decha Wiwatwitaya (Kasetsart University, Bangkok, Thailand) and Rumsaïs Blatrix (CEFE/CNRS, Montpellier, France). Material containing fungi and other microsymbionts was dried in silica gel. One sample was collected in Trat (Trat Province, Thailand) in July 2018 and processed in the same way as those from Rayong.

Two additional samples of pitcher leaves containing Philidris ants were collected in Rayong Botanical Garden in September 2018 and brought to Montpellier, France, where isolation of pure cultures of fungal strains was performed at the CEFE (Montpellier, France) following the procedure in Voglmayr et al. (2011). Pieces of the dark material containing fungal hyphae were scraped from within domatia with a sterilized pin, transferred to a drop of sterile water containing antibiotics $(0.04 \%$ 
streptomycin and $0.04 \%$ ampicillin) and torn apart with a fine scalpel. The solution was spread onto $2 \%$ malt extract agar plates and inspected under a microscope. Only melanized, thick-walled hyphae were present. Plates were incubated at room temperature and inspected under a stereomicroscope twice a day for five days to remove contaminants (i.e. hyphae growing from spores, which are fast-growing and hyaline). Germinating melanized hyphae were transferred to new plates. We obtained 21 pure cultures of melanized fungi.

DNA extraction and amplification by Polymerase Chain Reaction (PCR) were performed using the REDExtract-N-Amp PCR Kit (Sigma-Aldrich, St. Louis, Missouri, USA). Conditions for PCR first followed manufacturer's instructions, and were then adjusted if amplification failed. Target taxonomic groups were defined as Formicidae, Ascomycota, Trentepohliaceae and Trebouxia based on morphological investigation of the material from within pitcher leaves using a stereomicroscope and a compound microscope. Primer pairs specific to these groups were used to amplify part of the gene coding for the cytochrome c oxidase subunit I for ants (COI, c. 650 bp, primer pairs LepF1: 5'-ATTCAACCAATCATAAAGATAT-3' and LepR1: 5'TAAACTTCTGGATGTCCAAAAA-3', Hebert et al. 2004), part of the 18S rRNA gene for Trentepohliaceae algae (18S, c. 720 bp, primer pairs Tre18S_N5a_for: 5'TAGCATGGGATGACACGATAGGA-3' and CHtrente2.rev: 5'ACAAAGCTCTAGCCCCATCA-3', Hametner et al. 2014), and the internal transcribed spacer of the nuclear ribosome for Trebouxia algae (ITST, c. 730 bp, primer pairs ITS1T: 5'-GGAAGGATCATTGAATCTATCGT-3' and ITS4T: 5'GGTTCGCTCGCCGCTACTA-3', Kroken \& Taylor 2000) and for fungi (ITS, c. 
600 bp, primer pairs ITS1f: 5'-CTTGGTCATTTAGAGGAAGTAA-3' and ITS4: 5'TCCTCCGCTTATTGATATGC-3', White et al. 1990; Gardes \& Bruns 1993). Sanger dideoxy sequencing of PCR products was performed by Eurofins Genomics (Ebersberg, Germany) in both directions using the same primers as those used for the initial amplification. Sequences were edited using CodonCode Aligner (CodonCode Corporation, Dedham, MA, USA), and contigs were built from forward and reverse sequences generated for each gene. Conflicting base calls were coded using the ambiguity code. Sequences were deposited in GenBank. Sequences were aligned with MuSCLE (Edgar 2004). Alignments were inspected visually and edited manually using MESQUITE v. 3.31 (Maddison \& Maddison 2017) when they could be improved. Genetic distances were estimated in MESQUITE using the Kimura 2-parameter model (K2p).

We used the BLAST algorithm (https://blast.ncbi.nlm.nih.gov) to search GenBank for the closest relatives of sequences obtained from fungal pure cultures and from environmental samples of material from within domatia (fungi and algae). Fungal sequences were also searched for in the UNITE fungal ITS database (https://unite.ut.ee/ analysis.php\#) to assist identification. In addition, we built a maximum likelihood phylogeny with the PhyML online tool (Guindon et al. 2010) using the ITS sequences of our samples along with closely related GenBank sequences which choice was guided by the results from the BLAST algorithm and by the phylogenies of Crous et al. (2009) for Capnodiales and of Vasse et al. (2017) for Chaetothyriales. Morphological identification of black fungi (among which are orders Chaetothyriales and Capnodiales) is most often impossible, not to mention that many species remain to be described. Thus, we relied only on sequences of the ITS, as it is considered to be the best marker 
for discriminating species (Schoch et al. 2012). We considered a cut-off similarity of $99 \%$ between ITS sequences to delineate species, as this seems to be the most appropriate cut-off point for filamentous fungi (Vu et al. 2019). Morphological identification of the ants to genus was based on Shattuck (1992). As morphological identification of dolichoderine ants can be difficult, in particular for Thailand, we built a maximum likelihood phylogeny with the PhyML online tool (Guindon et al. 2010) using the COI sequence of our samples along with sequences available in GenBank for the genus we identified (Philidris) and for the most closely related genera (Anonychomyrma, Froggattella, Iridomyrmex, Linepithema, Ochetellus, Papyrius), chosen following the most recent phylogeny of dolichoderine ants (Ward et al. 2010). Most Philidris sequences used were issued from the largest phylogeny of the genus (Chomicki et al. 2017). However, we only used one or two sequences for each taxon for which COI sequences were available.

\section{Results}

Among the 26 D. major plants investigated, one was occupied by a Camponotus species and the 25 others were occupied by a single morphospecies that we identified as belonging to the genus Philidris. However, we had doubts about our morphological identification as none of the samples had the polymorphic workers typical of most Philidris species. The two COI sequences, from Rayong and Trat (GenBank accessions MW033977and MW033978, respectively), were identical and blasted at $99 \%$ with 
Philidris. Concomitantly, these sequences fit within the monophyletic clade formed by Philidris COI sequences in the phylogenetic tree (Fig. 2). In the absence of worker polymorphism in our nest samples and in regard to biogeography and morphology, the other candidate genus could have been Anonychomyrma. However, sequences from our samples and from Anonychomyrma species in GenBank were well separated in the phylogenetic tree (Fig. 2) and had a K2p genetic distance of $20 \%$.

Several Philidris colonies extended their nest outside pitcher leaves, into the bark of the support tree, and/or built a shelter around the space at the interface between the support tree and stems and roots of their Dischidia host (Fig. 1B). In addition, the ants built carton structures within pitcher leaves, sometimes embedding adventitious roots (Fig. 1C). Visual inspection of the inside of pitcher leaves revealed a black and a green lining on the inner surface of the leaf and on adventitious roots (Fig. 1D, E). These linings were more or less conspicuous and many pitcher leaves seemed not to bear them. Investigation of samples with the most conspicuous linings using a compound microscope suggested the black lining corresponded to black fungi typically found in other ant-plant symbioses (Mayer et al. 2014) and the green lining corresponded to Trebouxia and Trentepohliaceae algae, recognizable respectively by their coccoid cells and multicellular filaments (Fig. 1F, G). These two kinds of algae are commonly found in terrestrial habitats (e.g., Zhu et al. 2017; Xu et al. 2020). Trebouxia could be identified morphologically by its distinguishing characters, namely being unicellular and with each cell having one axial plastid with a central pyrenoid. Trentepohliaceae could also be identified morphologically by the presence of a filamentous structure, each cell in the structure with green discoid pyrenoid-less plastids and conspicuous 
orange droplets composed of lipids with dissolved carotenoids (Fig. 1F, G). Visual inspection of additional pitcher leaves from leaf clusters unoccupied by ants did not reveal any particular lining (Fig. 1H). However, we cannot exclude the presence of black fungi and algae in these samples.

Fungi and both kinds of algae were found intermingled, forming a biofilm on the inner surfaces of pitcher leaves and on adventitious roots (Fig. 1G). Amplification from environmental samples of these linings using primers specific to Trebouxia failed. The eight sequences obtained with primers specific to Trentepohliaceae blasted with the $18 \mathrm{~S}$ of various genera in the plant family Apocynaceae, suggesting that we amplified host plant DNA instead of algal DNA (data not shown). The two sequences (both from Rayong) obtained with primers specific to fungi matched a chaetothyrialean strain previously isolated from an ant-plant symbiosis in Cameroon (Table 1, Fig. 3).

We classified the 21 pure cultures of fungi into eight molecular taxonomic units (MOTUs) (Table 1, Fig. 3) based on their ITS sequences. Among the 21 pure cultures, eight and six belonged to MOTUs TPDM07 and TPDM14, respectively. These two MOTUs were thus the most abundant ones and were found in both fresh samples used for isolation of fungal strains. The other MOTUs were represented by only one or two strains. One strain of each MOTU was deposited at the culture collection of Westerdijk Fungal Biodiversity Institute (CBS), The Netherlands. Four MOTUs were Chaetothyriales and four were Capnodiales. Six MOTUs matched described species recorded in GenBank, one of which had already been isolated from ant-plant symbioses in South America (Table 1, Fig. 3). One MOTU matched an undescribed species and one did not match any strain recorded in GenBank. The UNITE database did not return 
better matches than GenBank. Only MOTU TPDM20 had high matches in both databases: 99 \% identity with Cladosporium delicatulum in UNITE and $100 \%$ identity with Cladosporium tenellum in GenBank.

\section{Discussion}

Our investigation provides new information on microbial associates of the symbiosis between $D$. major and Philidris ants, complementing the previous studies on this system (e.g. Kerr 1912; Janzen 1974; Treseder et al. 1995; Kaufmann and Maschwitz 2006; Peeters and Wiwatwitaya 2014), which focused primarily on the interaction between ants and their host plant. We show that pitcher leaves occupied by ants host various species of chaetothyrialean and capnodialean fungi, a phenomenon known in most ant-plant symbioses investigated to date (Mayer et al. 2014). More surprisingly, we reveal the occurrence of algae as additional associates.

According to our morphological and molecular investigation of ants dwelling in D. major in Rayong and Trat, we are confident that all the specimens we investigated belong to a single species of Philidris (except one Camponotus nest). However, we cannot provide a species designation. There are still many species of Philidris to be described, and the one from Rayong and Trat may be one of them. The record of Philidris in D. major geographically nearest to ours is that described by Peeters and Wiwatwitaya (2014) in the Nakhon Ratchasima province, about 200 km north of Rayong. They described a strong polymorphism in the ants from their nest samples. It is unlikely that the specimens from Rayong and Trat belong to the same species as those 
described by Peeters and Wiwatwitaya (2014) because our specimens did not show any conspicuous polymorphism.

The fungal species we characterized within pitcher leaves of D. major occupied by Philidris ants differed depending on whether we used direct sequencing of environmental samples or isolation of pure cultures. Each method has its flaws and the two can be complementary. As environmental samples usually contain several species mixed, sequencing is biased by the relative amount of matrix DNA for each species and by quality of primer annealing on matrix DNA. Isolation of pure cultures is biased by the differing capacity of fungal species to grow on culture medium. Combining both methods, we found nine species of black fungi in pitcher leaves of $D$. major occupied by Philidris ants. Two were chaetothyrialean species already known from other antplant symbioses in Africa and South America, one of which is known only from antplant symbioses (Voglmayr et al. 2011), while the other is Exophiala oligosperma Calendron ex De Hoog \& Tintelnot, known from various environmental substrates and reported to be an opportunistic human pathogen (de Hoog et al. 2003). Two were chaetothyrialean species, Cyphellophora guyanensis Decock and G. Delgado and Fonsecaea minima V.A. Vicente, Najafz., J.F. Sun and de Hoog, both known from plant material in South America (Decock et al. 2003; Feng et al. 2012; Vicente et al. 2014). These two species have never been recorded as human pathogens, although many closely related species are (Feng et al. 2012; Vicente et al. 2014). Three were the capnodialean species Leptoxyphium fumago (Woron.) Crous, found from the surfaces of leaves in Asia (Yang et al. 2014; Crous et al. 2020), Cladosporium halotolerans Zalar, de Hoog and Gunde-Cim. and Cladosporium tenellum K. Schubert, Zalar, Crous and U. 
Braun, both known worldwide mostly from indoor environments, plant material and hypersaline water in salterns (Schubert et al. 2007; Bensch et al. 2018; Du et al. 2020), and one an undescribed capnodialean taxon retrieved from pages of a more than 1000year-old parchment (Piñar et al. 2015). One other did not match any record in GenBank and may be a new species. The apparent inconsistency among the various habitats of the species identified above is a common phenomenon in Chaetothyriales and Capnodiales. Black fungi are usually slow-growing but can withstand extreme conditions. The extreme nature of one or more environmental conditions is the property common to all these habitats and most likely explains their colonization by these fungi. The antimicrobial substances produced by ants (Yek and Mueller 2011) may screen out most fungi, making ant nests a free niche for colonization by black fungi. This may explain why black fungi have been found associated with so many ant-plant symbioses (Mayer et al. 2014). Although the symbiotic nature of the ant-plant-fungus association has been demonstrated in a few systems, in most cases it remains unclear whether the fungal associates are true symbionts. Their presence might in some cases simply be fortuitous. The lack of knowledge on black fungi precludes testing this hypothesis. In the case of D. major, we did not look for black fungi in plants without ants, so that we can hardly qualify black fungi as true symbionts.

This is the first study that reports the presence of algae living in association with ant-occupied domatia of myrmecophytes. This finding supports the results of a previous study that suggested that the organisms recorded in ant-occupied domatia of myrmecophytes are diverse (Blatrix et al. 2009). In this study, we successfully identified the algae based on their distinguishing morphological characters using 
compound light microscopy. However, we were unable to amplify the algal gene markers from the extracted genomic DNA. DNA barcodes used for Viridiplantae are likely to amplify the host (as happened in our case) and databases are lacking that would permit designing suitable primers more specific to this group of algae.

The presence of Trebouxia and Trentepohliaceae algae living in dark environments documented in this study suggested that these algae found in association with ant-occupied domatia of myrmecophytes might be mixotrophs — organisms that can acquire nutrition both by performing photosynthesis and by utilizing organic carbon from other sources in the absence of light. Although mixotrophy is so far unknown in Trentepohliaceae, some Trebouxia species are reported to be mixotrophs (Archibald 1977). In this study, mixotrophic algae might be able to acquire organic carbon from the fungal or plant exudates, as it has been shown that lichen-forming algae can also receive organic carbon-containing molecules, e.g., glucose, from the lichen mycobiont (Du et al. 2019).

The most intriguing observation is the formation on the surfaces of adventitious roots and pitcher leaves of a biofilm-like structure composed of coccoid cells of Trebouxia embedded in intermingled filaments of black fungi and Trentepohliaceae. Interestingly, several capnodialean species are known to form lichens with Trentepohliaceae (Muggia et al. 2008). In addition, Chaetothyriales are able to form physical associations and even lichen-like structures with green algae, including Trebouxia, when co-cultured in vitro (Gorbushina et al. 2005; Brunauer et al. 2007; Muggia and Grube 2018). The exact nature of the co-occurrence of black fungi and algae within domatia still remains to be elucidated and is worthy of investigation 
because Capnodiales and Chaetothyriales may be predisposed to form symbiotic associations with algae (Muggia et al. 2013). Further work should focus on functional relationships not only between the fungi and the algae, but also those between these organisms and the host plant and the ants. This will aid our understanding of how interactions between algae and fungi within domatia interact with the ants and host plant.

Interactions between ants and myrmecophytic plants have been used repeatedly and in many contexts as a model for the study of symbiosis. Yet, many aspects of the biology of these interactions remain poorly understood. Our study provides an example of why associations between ant-plant symbioses and fungi in the orders Chaetothyriales and Capnodiales, and with algae, should be considered. It also highlights that a lack of knowledge on the ecology of the fungi and algae, and on their interactions with the plant and its ants, limits ecological and evolutionary interpretation of patterns in these associations.

\section{Acknowledgments}

We thank all the reviewers for their time spent and their constructive criticisms. We thank Marie-Pierre Dubois for providing facilities for molecular biology bench work. We also thank Phattaravee Prommanut for his enthusiastic help during fieldwork. Data used in this work were partly produced through the GEMEX technical facilities of the Centre d'Ecologie Fonctionnelle et Evolutive with the support of LabEx CeMEB, an 
ANR Investissements d'avenir program (ANR-10-LABX-04-01).This research was supported by the 'Franco-Thai Mobility Programme (PHC SIAM, France) 2018-2019' (project number 40533RA), by the programme 'International Emerging Actions' of the CNRS, France (project FOOLFLY 2020-2021), and by Chulalongkorn University: CUGR_61_020_23_007.

\section{References}

Archibald PA (1977) Physiological characteristics of Trebouxia (Chlorophyceae, Chlorococcales) and Pseudotrebouxia (Chlorophyceae, Chlorosarcinales). Phycologia 16: 295-300.

Bailey IW (1922) The anatomy of certain plants from the Belgian Congo, with special reference to myrmecophytism. Bull Am Mus Nat Hist 45: 585-621.

Bensch K, Groenewald JZ, Meijer M, Dijksterhuis J, Jurjević Ž, Andersen B, Houbraken J, Crous PW, Samson RA (2018) Cladosporium species in indoor environments. Stud Mycol 89: 177-301.

Blatrix R, Bouamer S, Morand S, Selosse MA (2009) Ant-plant mutualisms should be viewed as symbiotic communities. Plant Signal Behav 4: 554-556.

Blatrix R, Debaud S, Salas-Lopez A, Born C, Benoit L, McKey D, Atteke C, DjiétoLordon C (2013) Repeated evolution of fungal cultivar specificity in independently evolved ant-plant-fungus symbioses. PloS ONE 8: e68101.

Blatrix R, Djiéto-Lordon C, Mondolot L, La Fisca P, Voglmayr H, McKey D (2012) Plant-ants use symbiotic fungi as a food source: new insight into the nutritional ecology of ant-plant interactions. Proc R Soc B Biol Sci 279: 3940-3947. 
Brunauer G, Blaha J, Hager A, Tuerk R, Stocker-Wörgötter E, Grube M (2007) An isolated lichenicolous fungus forms lichenoid structures when co-cultured with various coccoid algae. Symbiosis 44: 127-136.

Chomicki G, Renner SS (2015) Phylogenetics and molecular clocks reveal the repeated evolution of ant-plants after the late Miocene in Africa and the early Miocene in Australasia and the Neotropics. New Phytol 207: 411-424.

Chomicki G, Janda M, Renner SS (2017) The assembly of ant-farmed gardens: mutualism specialization following host broadening. Proc R Soc B: Biol Sci 284: 20161759.

Crous PW, Schoch CL, Hyde KD, Wood AR, Gueidan C, De Hoog GS, Groenewald JZ (2009) Phylogenetic lineages in the Capnodiales. Stud Mycol 64: 17-47.

Crous PW, Wingfield MJ, Schumacher RK, Akulov A, Bulgakov TS, Carnegie AJ, Jurjević Ž, Decock C, Denman S, Lombard L (2020) New and Interesting fungi. 3. Fungal Syst Evol 6: 157.

Davidson DW, McKey D (1993) The evolutionary ecology of symbiotic ant-plant relationships. J Hymenopt Res 2: 13-83.

Decock C, Delgado-Rodríguez G, Buchet S, Seng JM (2003) A new species and three new combinations in Cyphellophora, with a note on the taxonomic affinities of the genus, and its relation to Kumbhamaya and Pseudomicrodochium. Antonie van Leeuwenhoek 84: 209.

Defossez E, Djiéto-Lordon C, McKey D, Selosse MA, Blatrix R (2011) Plant-ants feed their host plant, but above all a fungal symbiont to recycle nitrogen. Proc R Soc B Biol Sci 278: 1419-1426. 
Defossez E, Selosse MA, Dubois MP, Mondolot L, Faccio A, Djiéto-Lordon C, McKey D, Blatrix R (2009) Ant-plants and fungi: a new threeway symbiosis. New Phytol 182: 942-949.

Dejean A, Solano PJ, Ayroles J, Corbara B, Orivel J (2005) Arboreal ants build traps to capture prey. Nature 434: 973.

Du W, Yao Z, Li J, Sun C, Xia J, Wang B, Shi D, Ren L (2020) Diversity and antimicrobial activity of endophytic fungi isolated from Securinega suffruticosa in the Yellow River Delta. PLoS ONE 15: e0229589.

Du ZY, Zienkiewicz K, Pol NV, Ostrom NE, Benning C, Bonito GM (2019) Algalfungal symbiosis leads to photosynthetic mycelium. eLife 8: e47815.

Edgar RC (2004) MUSCLE: multiple sequence alignment with high accuracy and high throughput. Nucleic Acids Res 32: 1792-1797.

Feng P, Lu Q, Najafzadeh MJ, van den Ende A, Sun J, Li R, Xi L, Vicente VA, Saunte DL, de Hoog HS (2012) Cyphellophora and its relatives in Phialophora: Biodiversity and their possible role in human infection. Mycoses 55: 255-255.

Gardes M, Bruns TD (1993) ITS primers with enhanced specificity for basidiomycetes Application to the identification of mycorrhizae and rusts. Mol Ecol 2: 113-118. Gegenbauer C, Mayer VE, Zotz G, Richter A (2012) Uptake of ant-derived nitrogen in the myrmecophytic orchid Caularthron bilamellatum. Ann Bot 110: 757-765.

Gorbushina AA, Beck A, Schulte A (2005) Microcolonial rock inhabiting fungi and lichen photobionts: evidence for mutualistic interactions. Mycol Res 109: 12881296.

Gostinčar C, Muggia L, Grube M (2012) Polyextremotolerant black fungi: 
oligotrophism, adaptive potential, and a link to lichen symbioses. Front Microbiol 3: 390.

Griffith W, Solly RH (1851) On the structure of the ascidia and stomata of Dischidia rafflesiana Wall. Trans Linn Soc London 20: 387-390.

Guindon S, Dufayard JF, Lefort V, Anisimova M, Hordijk W, Gascuel O (2010) New algorithms and methods to estimate maximum-likelihood phylogenies: assessing the performance of PhyML 3.0. Syst Biol 59: 307-321.

Hametner C, Stocker-Wörgötter E, Grube M (2014) New insights into diversity and selectivity of trentepohlialean lichen photobionts from the extratropics. Symbiosis 63: 31-40.

Hanshew AS, McDonald BR, Díaz CD, Djiéto-Lordon C, Blatrix R, Currie CR (2015) Characterization of actinobacteria associated with three ant-plant mutualisms. Microb Ecol 69: 192-203.

Hebert PDN, Penton EH, Burns JM, Janzen DH, Hallwachs W (2004) Ten species in one: DNA barcoding reveals cryptic species in the neotropical skipper butterfly Astraptes fulgerator. Proc Natl Acad Sci U S A 101: 14812-14817.

Heil M, McKey D (2003) Protective ant-plant interactions as model systems in ecological and evolutionary research. Annu Rev Ecol Evol Syst 34: 425-453. de Hoog GS, Vicente V, Caligiorne RB, Kantarcioglu S, Tintelnot K, van den Ende AHGG, Haase G (2003) Species diversity and polymorphism in the Exophiala spinifera clade containing opportunistic black yeast-like fungi. J Clin Microbiol 41: 4767-4778.

Huxley CR (1978) Ant-plants Myrmecodia and Hydnophytum (Rubiaceae), and the 
relationships between their morphology, ant occupants, physiology and ecology. New Phytol 80: 231-268.

Janzen DH (1972) Protection of Barteria (Passifloraceae) by Pachysima ants (Pseudomyrmecinae) in a Nigerian rain forest. Ecology 53: 885-892. Janzen DH (1974) Epiphytic myrmecophytes in Sarawak: mutualism through the feeding of plants by ants. Biotropica 6: 237-259.

Kaufmann E (2002) Southeast Asian ant-gardens. PhD Thesis. Goethe Universität, Frankfurt, Germany, 203 pp.

Kaufmann E, Maschwitz U (2006) Ant-gardens of tropical Asian rainforests. Naturwissenschaften 93: 216-227.

Kerr AFG (1912) Notes on Dischidia rafflesiana Wall. and Dischidia nummularia, Blume. Sci Proc R Dublin Soc 13: 292-315.

Kokolo B, Atteke C, Ibrahim B, Blatrix R (2016) Pattern of specificity in the tripartite symbiosis between Barteria plants, ants and Chaetothyriales fungi. Symbiosis 69: $169-174$.

Kroken S, Taylor JW (2000) Phylogenetic species, reproductive mode, and specificity of the green alga Trebouxia forming lichens with the fungal genus Letharia. Bryologist 103: 645-660.

Leroy C, Jauneau A, Martinez Y, Cabin-Flaman A, Gibouin D, Orivel J, SéjalonDelmas N (2017) Exploring fungus-plant N transfer in a tripartite ant-plantfungus mutualism. Ann Bot 120: 417-426.

Leroy C, Sejalon-Delmas N, Jauneau A, Ruiz-Gonzalez MX, Gryta H, Jargeat P, Corbara B, Dejean A, Orivel J (2011) Trophic mediation by a fungus in an ant- 
plant mutualism. J Ecol 99: 583-590.

Livshultz T, Bach A (2005) Dischidia (Apocynaceae, Asclepiadoideae) in Laos and Vietnam. Blumea 50: 113-134.

Maddison WP, Maddison DR (2017) Mesquite: a modular system for evolutionary analysis. v 3.31 http://mesquiteproject.org.

Maschwitz U, Fiala B, Dumpert K, bin Hashim R, Sudhaus W (2016) Nematode associates and bacteria in ant-tree symbioses. Symbiosis 69: 1-7.

Mayer VE, Frederickson ME, McKey D, Blatrix R (2014) Current issues in the evolutionary ecology of ant-plant symbioses. New Phytol 202: 749-764.

Mayer VE, Nepel M, Blatrix R, Oberhauser FB, Fiedler K, Schönenberger J, Voglmayr H (2018) Transmission of fungal partners to incipient Cecropia-tree ant colonies. PloS ONE 13: e0192207.

Mayer VE, Voglmayr H (2009) Mycelial carton galleries of Azteca brevis (Formicidae) as a multi-species network. Proc R Soc B Biol Sci 276: 3265-3273.

Miehe H (1911) Untersuchungen über die javanische Myrmecodia. Abhandlungen der Mathematisch-Physischen Klasse der Königlich-Sächsischen Gesellschaft der Wissenschaften 32: 312-361.

Muggia L, Grube M (2018) Fungal diversity in lichens: from extremotolerance to interactions with algae. Life 8: 15.

Muggia L, Gueidan C, Knudsen K, Perlmutter G, Grube M (2013) The lichen connections of black fungi. Mycopathologia 175: 523-535.

Muggia L, Hafellner J, Wirtz N, Hawksworth DL, Grube M (2008) The sterile microfilamentous lichenized fungi Cystocoleus ebeneus and Racodium rupestre 
are relatives of plant pathogens and clinically important dothidealean fungi. Mycol Res 112: 50-56.

Nascimento MMF, Selbmann L, Sharifynia S, Al-Hatmi AMS, Voglmayr H, Vicente VA, Deng S, Kargl A, Moussa TAA, Al-Zahrani HS, Almaghrabi OA, de Hoog SG (2016) Arthrocladium, an unexpected human opportunist in Trichomeriaceae (Chaetothyriales). Fungal Biol 120: 207-218.

Nepel M, Voglmayr H, Blatrix R, Longino JT, Fiedler K, Schönenberger J, Mayer VE (2016) Ant-cultivated Chaetothyriales in hollow stems of myrmecophytic Cecropia sp. trees - diversity and patterns. Fungal Ecol 23: 131-140.

Nepel M, Voglmayr H, Schönenberger J, Mayer VE (2014) High diversity and low specificity of Chaetothyrialean fungi in carton galleries in a neotropical ant-plant association. PloS One 9: e112756.

Pearson HHW (1902) On some species of Dischidia with double pitchers. Bot J Linn Soc 35: 375-390.

Peeters C, Wiwatwitaya D (2014) Philidris ants living inside Dischidia epiphytes from Thailand. Asian Myrmecology 6: 49-61.

Piñar G, Sterflinger K, Ettenauer J, Quandt A , Pinzari F (2015) A combined approach to assess the microbial contamination of the Archimedes Palimpsest. Microb Ecol 69: $118-134$.

Rintz RE (1980) The Peninsular Malayan species of Dischidia (Asclepiadaceae). Blumea 26: 81-126.

Ruiz-González MX, Male PJG, Leroy C, Dejean A, Gryta H, Jargeat P, Quilichini A, Orivel J (2011) Specific, non-nutritional association between an ascomycete 
fungus and Allomerus plant-ants. Biol Lett 7: 475-479.

Schoch CL, Seifert KA, Huhndorf S, Robert V, Spouge JL, Levesque CA, Chen W, Bolchacova E, Voigt K, Crous PW, Miller AN, Wingfield MJ, Aime MC, An KD, Bai FY, Barreto RW, Begerow D, Bergeron MJ, Blackwell M, Boekhout T, Bogale M, Boonyuen N, Burgaz AR, Buyck B, Cai L, Cai Q, Cardinali G, Chaverri P, Coppins BJ, Crespo A, Cubas P, Cummings C, Damm U, de Beer ZW, de Hoog GS, Del-Prado R, Dentinger B, Dieguez-Uribeondo J, Divakar PK, Douglas B, Duenas M, Duong TA, Eberhardt U, Edwards JE, Elshahed MS, Fliegerova K, Furtado M, Garcia MA, Ge ZW, Griffith GW, Griffiths K, Groenewald JZ, Groenewald M, Grube M, Gryzenhout M, Guo LD, Hagen F, Hambleton S, Hamelin RC, Hansen K, Harrold P, Heller G, Herrera G, Hirayama K, Hirooka Y, Ho HM, Hoffmann K, Hofstetter V, Hognabba F, Hollingsworth PM, Hong SB, Hosaka K, Houbraken J, Hughes K, Huhtinen S, Hyde KD, James T, Johnson EM, Johnson JE, Johnston PR, Jones EB, Kelly LJ, Kirk PM, Knapp DG, Koljalg U, Kovacs GM, Kurtzman CP, Landvik S, Leavitt SD, Liggenstoffer AS, Liimatainen K, Lombard L, Luangsa-Ard JJ, Lumbsch HT, Maganti H, Maharachchikumbura SS, Martin MP, May TW, McTaggart AR, Methven AS et al (2012) Nuclear ribosomal internal transcribed spacer (ITS) region as a universal DNA barcode marker for fungi. Proc Natl Acad Sci U S A 109: 6241-6246.

Schremmer VF (1984) Untersuchungen und Beobachtungen zur Ökoethologie der Pflanzenameise Pseudomyrmex triplarinus, welche die Ameisenbäume der Gattung Triplaris bewohnt. Zoologische Jahrbücher, Abteilung für Systematik, Ökologie und Geographie der Tiere 111: 385-410. 
Schubert K, Groenewald JZ, Braun U, Dijksterhuis J, Starink M, Hill CF, Zalar P, De Hoog GS, Crous PW (2007) Biodiversity in the Cladosporium herbarum complex (Davidiellaceae, Capnodiales), with standardisation of methods for Cladosporium taxonomy and diagnostics. Stud Mycol 58: 105-156.

Shattuck SO (1992) Generic revision of the ant subfamily Dolichoderinae (Hymenoptera: Formicidae). Sociobiology 21: 1-181.

Thaithong O, Kidyoo M, Kidyoo A (2018) Handbook of Asclepiads of Thailand. Amarin Printing and Publishing, Bangkok.

Thompson JN (1981) Reversed animal-plant interactions: the evolution of insectivorous and ant-fed plants. Biol J Linn Soc Lond 16: 147-155.

Treseder KK, Davidson DW, Ehleringer JR (1995) Absorption of ant-provided carbondioxide and nitrogen by a tropical epiphyte. Nature 375: 137-139.

Vasse M, Voglmayr H, Mayer V, Gueidan C, Nepel M, Moreno L, de Hoog S, Selosse M-A, McKey D, Blatrix R (2017) A phylogenetic perspective on the association between ants (Hymenoptera: Formicidae) and black yeasts (Ascomycota: Chaetothyriales). Proc R Soc LondonB Biol Sci 284: 20162519.

Vicente VA, Najafzadeh MJ, Sun J, Gomes RR, Robl D, Marques SG, Azevedo C, de Hoog GS (2014) Environmental siblings of black agents of human chromoblastomycosis. Fungal Divers 65: 47-63.

Voglmayr H, Mayer V, Maschwitz U, Moog J, Djiéto-Lordon C, Blatrix R (2011) The diversity of ant-associated black yeasts: Insights into a newly discovered world of symbiotic interactions. Fungal Biol 115: 1077-1091.

Vu D, Groenewald M, De Vries M, Gehrmann T, Stielow B, Eberhardt U, Al-Hatmi A, 
Groenewald JZ, Cardinali G, Houbraken J (2019) Large-scale generation and analysis of filamentous fungal DNA barcodes boosts coverage for kingdom fungi and reveals thresholds for fungal species and higher taxon delimitation. Stud Mycol 92: 135-154.

Ward PS, Brady SG, Fisher BL, Schultz TR (2010) Phylogeny and biogeography of dolichoderine ants: Effects of data partitioning and relict taxa on historical inference. Syst Biol 59: 342-362.

Webber BL, Moog J, Curtis AS, Woodrow IE (2007) The diversity of ant-plant interactions in the rainforest understorey tree, Ryparosa (Achariaceae): food bodies, domatia, prostomata, and hemipteran trophobionts. Bot J Linn Soc, 154: 353-371.

White TJ, Bruns TD, Lee S, Taylor JW (1990) Amplification and direct sequencing of fungal ribosomal RNA genes for phylogenetics. In: Innis MA, Gelfand DH, Sninsky JJ, White TJ (eds) PCR protocols: a guide to methods and applications, Academic Press, San Diego, pp 315-322.

Yang H, Ariyawansa HA, Wu H-X, Hyde KD (2014) The genus Leptoxyphium (Capnodiaceae) from China. Phytotaxa 176: 174-183.

Yek SH, Mueller UG (2011) The metapleural gland of ants. Biol Rev 86: 774-791.

Xu M, De Boer H, Olafsdottir ES, Omarsdottir S, Heidmarsson S (2020) Phylogenetic diversity of the lichenized algal genus Trebouxia (Trebouxiophyceae, Chlorophyta): a new lineage and novel insights from fungal-algal association patterns of Icelandic cetrarioid lichens (Parmeliaceae, Ascomycota). Bot J Linn Soc. https://doi.org/10.1093/botlinnean/boaa050. 
Zhu H, Hu Z, Liu G (2017) Morphology and molecular phylogeny of Trentepohliales (Chlorophyta) from China. Eur J Phycol 52(3): 330 -341. 


\section{Tables}

Table 1. Information on fungal species occurring in cavities of pitcher leaves of Dischidia major occupied by Philidris ants in Thailand, based on their ITS sequences blasted on GenBank. Pure cultures were isolated from two fresh samples $\left({ }^{s 1}\right.$ and ${ }^{\mathrm{s} 2}$ : strains isolated from sample 1 and 2 respectively).

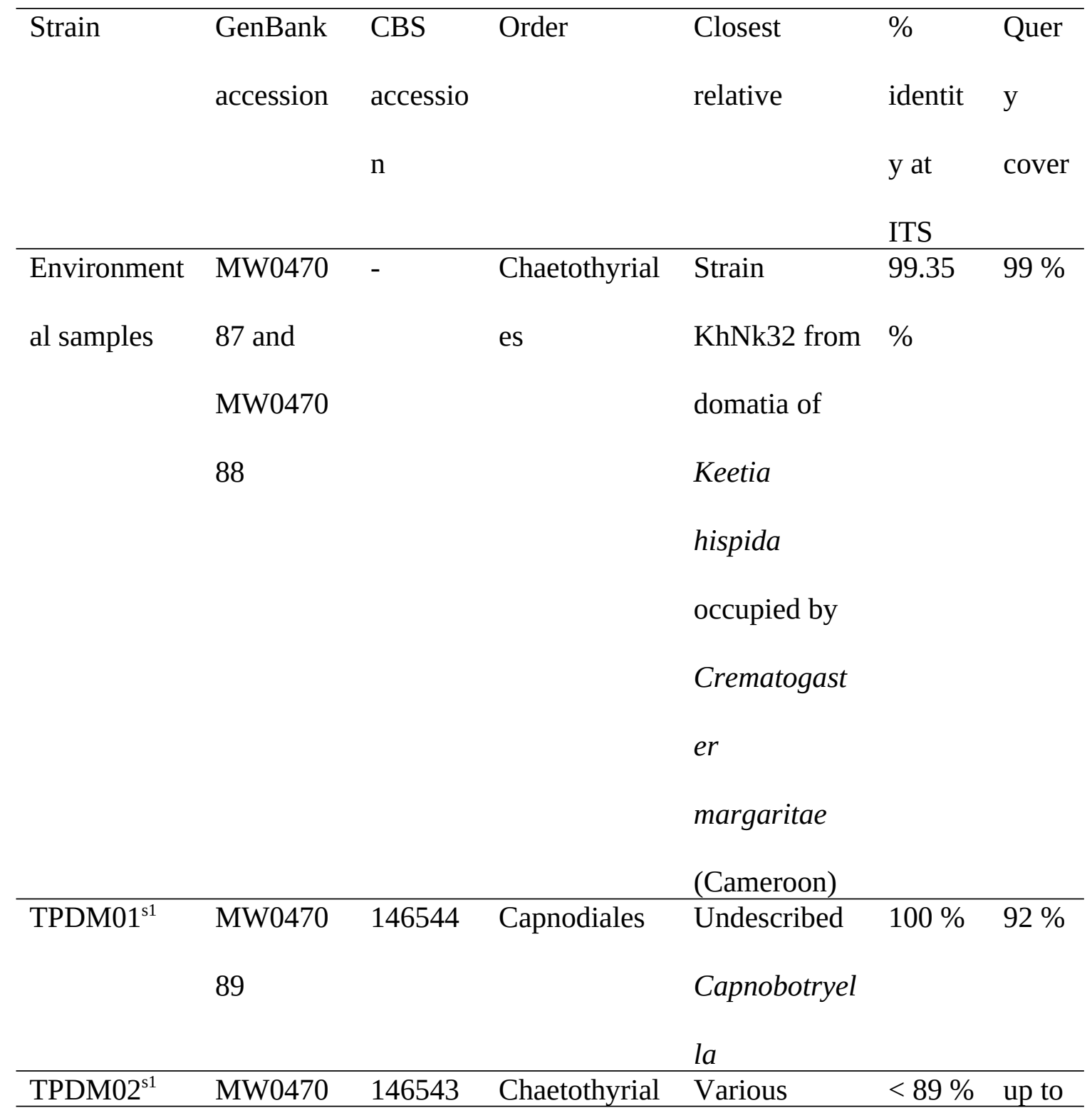




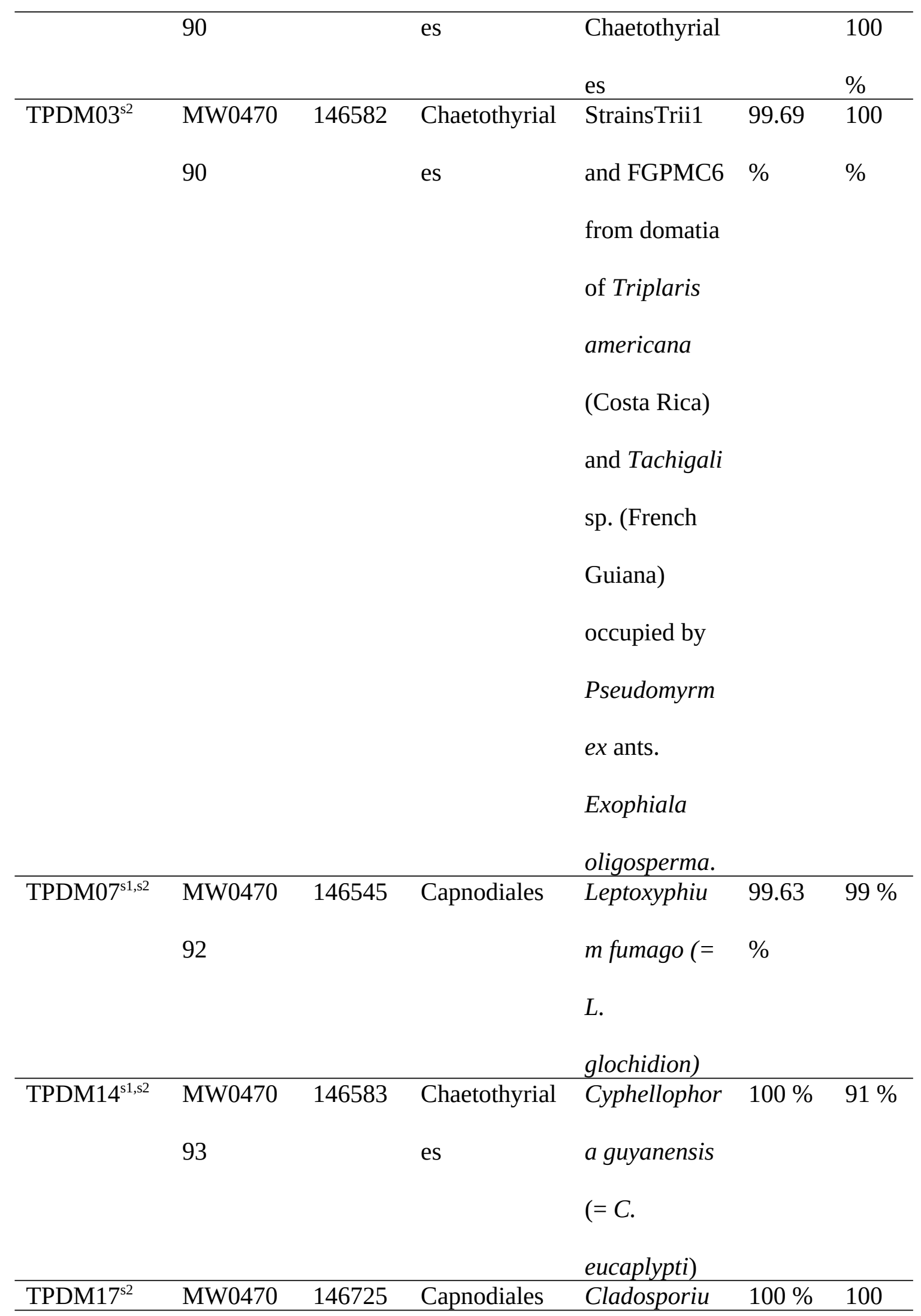




\begin{tabular}{lllllll}
\hline & 94 & & & $m$ & & $\%$ \\
& & & & & \\
& & & & halotolerans \\
TPDM20 $^{\text {s2 }}$ & MW0470 & 146546 & Capnodiales & Cladosporiu & $100 \%$ & 100 \\
& 95 & & & m tenellum & $\%$ \\
\hline TPDM21 $^{\text {s2 }}$ & MW0470 & 146584 & Chaetothyrial & Fonsecaea & $100 \%$ & 100 \\
& 96 & & & es & minima & \\
\hline
\end{tabular}




\section{Figure Captions}

Fig. 1 The association between the epiphyte Dischidia major, Philidris ants, black fungi (Chaetothyriales and Capnodiales) and algae. (A) Clusters of pitcher leaves (arrows) on a Melaleuca quinquenervia tree in the swamp of Rayong Botanical Garden, Thailand. (B) Cluster of pitcher leaves showing the shelter built by Philidris ants around the space at the interface between the support tree and stems and roots of the plant. (C) Pitcher leaf cut open showing the carton structures built by ants around adventitious roots. (D)

(E) Dark lining ranging from black (mostly black fungi) to green (mostly algae) covering the inner side of pitcher leaves and adventitious roots. The inner surface of the pitcher leaf is normally brown (D) to purple (E, H). (F) Compound microscopy image of filaments of Trentepohliaceae algae from the lining on the inner surface of a pitcher leaf. (G) Compound microscopy image of the biofilm-like structure formed on the inner surface of a pitcher leaf by intermingled coccoid Trebouxia cells (ac) and monilioid hyphae of black fungi (fh). (H) Pitcher leaf (cut open) of a leaf cluster unoccupied by ants, showing the inner surface and adventitious roots with no apparent black or green lining. Photo credits: Rumsaïs Blatrix (A-E, H), Manit Kidyoo (F, G).

Fig. 2 Maximum likelihood phylogeny of cytochrome c oxidase subunit I gene (COI) of the dolichoderine genera most closely related to Philidris. Numbers at nodes are bootstrap values. The sequence obtained in this study is in bold.

Fig. 3 Maximum likelihood phylogenies of the internal transcribed spacer region for 
sequences of Chaetothyriales and Capnodiales selected among the most closely related to the sequences obtained from dark linings within Dischidia major domatia. Numbers at nodes are bootstrap values. The sequences obtained in this study are in bold. 
Figure 1
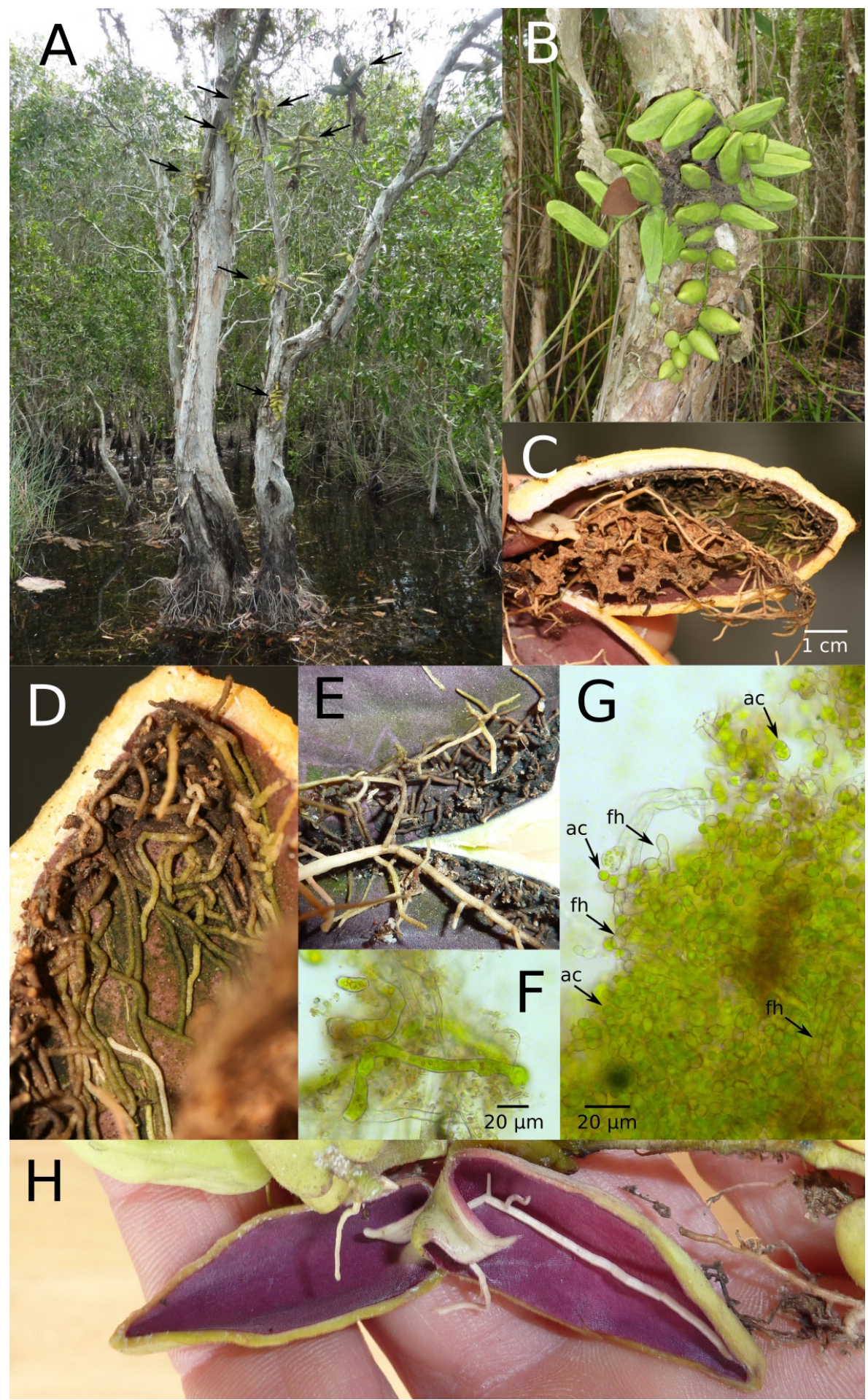
Figure 2

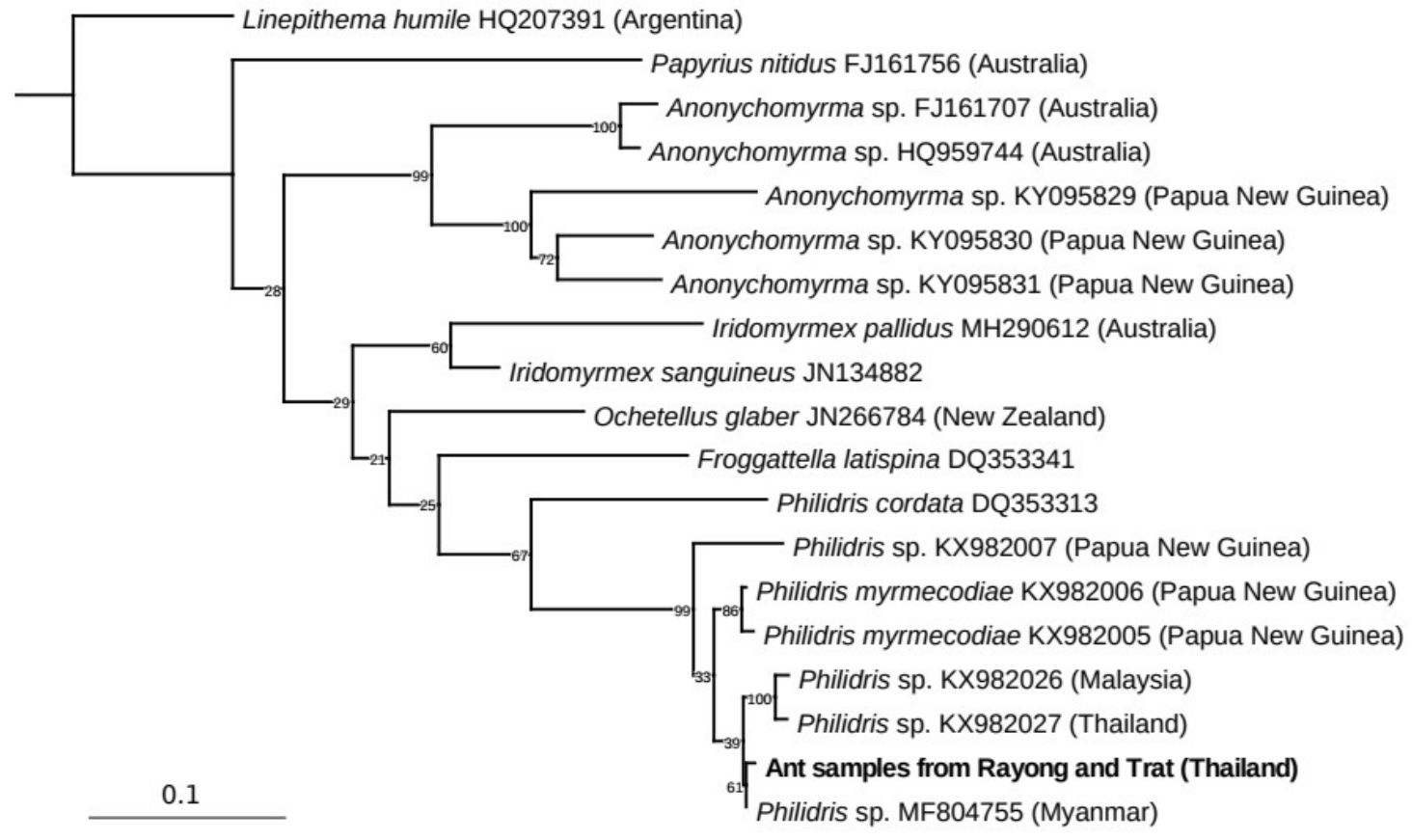


Figure 3

\section{Chaetothyriales}

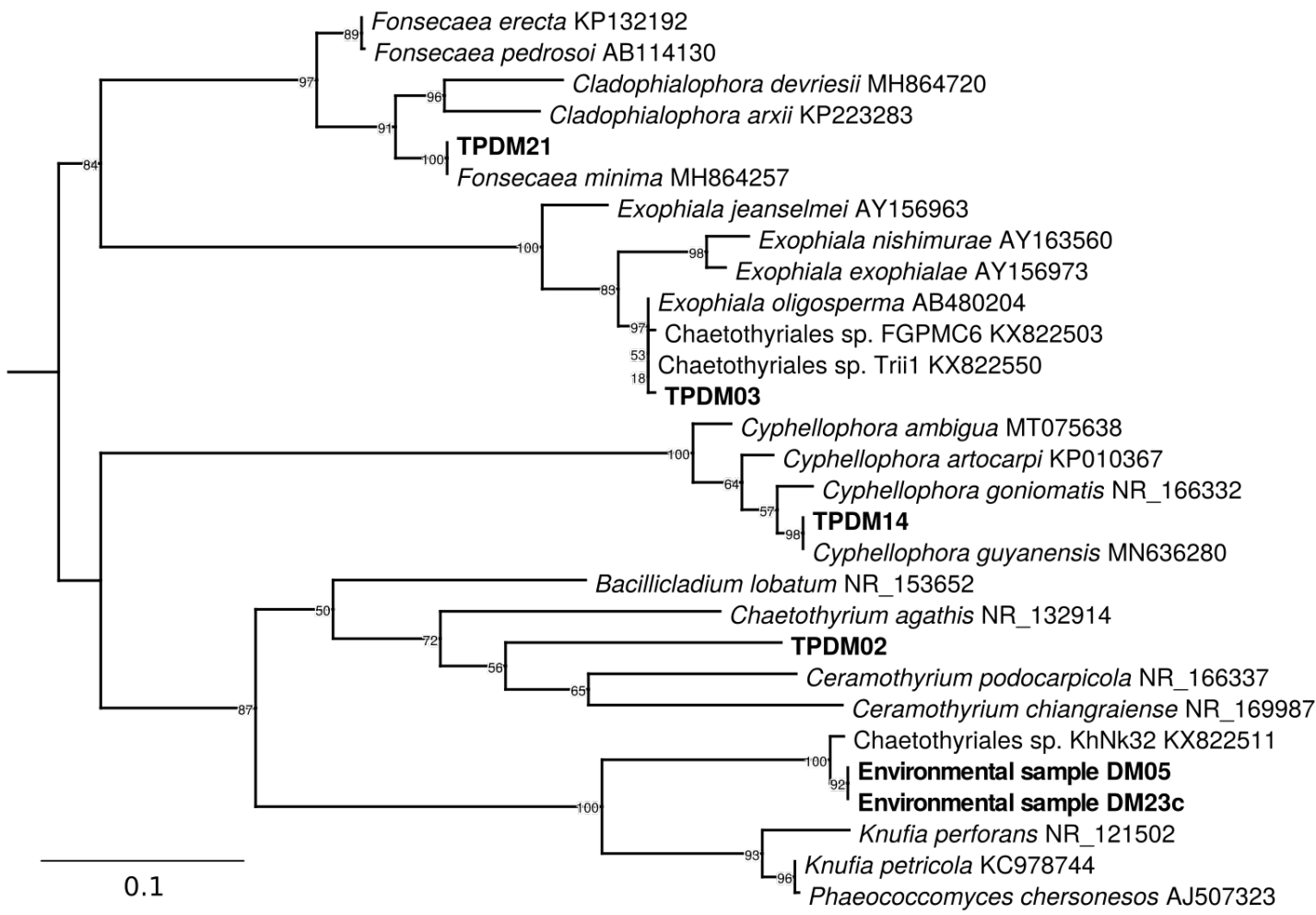

\section{Capnodiales}

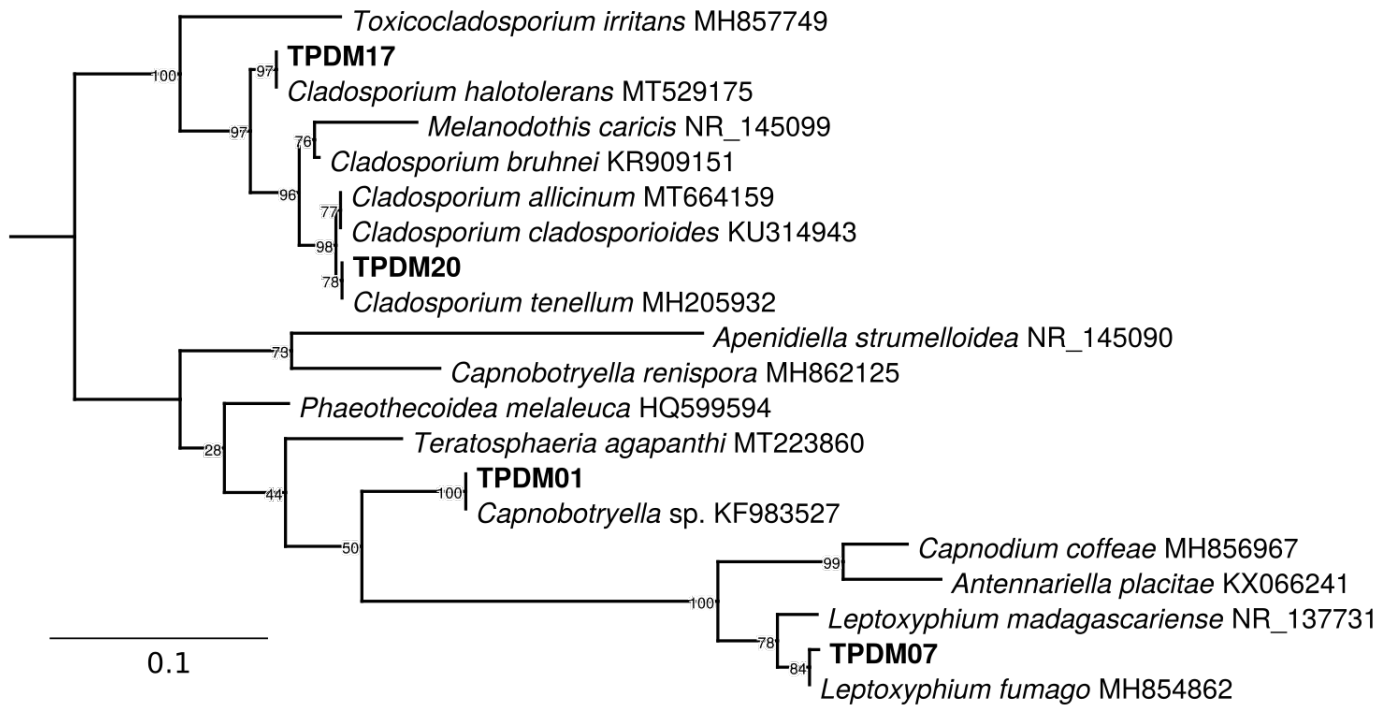

